See discussions, stats, and author profiles for this publication at: https://www.researchgate.net/publication/263745429

\title{
Efficiency and selectivity of triterpene acid extraction from decoctions and tinctures prepared from apple peels
}

Article in Pharmacognosy Magazine · April 2014

DOI: 10.4103/0973-1296.133236 · Source: PubMed

CITATIONS

5

6 authors, including:

José L Mazzei

Fundação Oswaldo Cruz

87 PUBLICATIONS 497 CITATIONS

SEE PROFILE

Some of the authors of this publication are also working on these related projects:

Project Cellular protection by moss extracts against ROS and UV-induced damages View project

Project Revista Fitos View project
READS

112

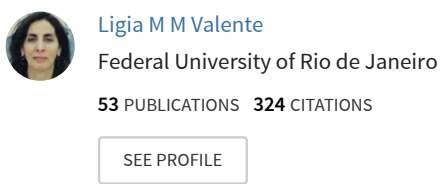




\title{
Efficiency and selectivity of triterpene acid extraction from decoctions and tinctures prepared from apple
} peels

\author{
Antonio C. Siani, Marcos J. Nakamura, Daniel S. dos Santos, José L. Mazzei, Adriana C. do Nascimento', \\ Ligia M. M. Valente ${ }^{1}$
}

Medicines and Drugs Technology Institute, Oswaldo Cruz Foundation, Rio de Janeiro, ${ }^{1}$ Department of Organic Chemistry, Chemistry Institute, Federal University of Rio de Janeiro, Rio de Janeiro, RJ, Brazil

Submitted: 18-07-2013

Revised: 29-08-2013

Published: 28-05-2014

A B S T R A C T

Background: This study assessed the extraction efficiency of ursolic (UA) and oleanolic acids (OA), as well as the total phenols in aqueous and hydroethanolic extracts of dry apple peels at room temperature. Materials and Methods: After running preliminary assays on decoctions and tinctures (ethanol: water 7:3 v/v), the extracts from dried apple (cv. Fuji) peels were obtained by static maceration over varied intervals ( 2 to 180 days). The UA and OA content in the extracts was quantified by High Performance Liquid Chromatography with Diode Array Detection (HPLC-DAD) with a reversed phase column and isocratic elution $\left(\mathrm{CH}_{3} \mathrm{CN} / \mathrm{H}_{2} \mathrm{O} / \mathrm{H}_{3} \mathrm{PO}_{4}\right)$ against calibration curves $\left(\mathrm{R}^{2}>0.9995\right)$. The total phenol content in the extracts was evaluated spectrophotometrically at $760 \mathrm{~nm}$ using the Folin-Ciocalteau method referencing gallic acid. Results: $\mathrm{UA}$ and $\mathrm{OA}$ in the hydroethanolic extracts ranged from $3.63-6.12 \mathrm{mg} / \mathrm{g}$ and $2.12-3.30 \mathrm{mg} / \mathrm{g}$, corresponding to $1.72-3.07$ and $1.00-1.66 \mathrm{mg} / \mathrm{g}$ in the raw material, respectively. Higher values of triterpene acid content corresponded to maceration periods of 10 or 30 days. The residual phenol and polyphenol content ranged from 6.97 to $11.6 \mathrm{mg} / \mathrm{g}$. The UA and OA yields, as well as the total phenol content, versus the maceration time were plotted in Control Charts within confidence intervals $(95 \%)$ and were unaffected during the assayed period. Conclusion: Apple peel tinctures from $10 \%$ solids obtained at room temperature exhibited the highest content of triterpene acids when employing a maceration period of 10 to 30 days. Extracts prepared using this procedure contained an average of $7.33 \mathrm{mg} / \mathrm{g}$ of total triterpene acids and $10.6 \mathrm{mg} / \mathrm{g}$ phenolic compounds. These results establish supporting data for apple peel tinctures and their derived phytopharmaceuticals that are standardized on the ursolic-oleanolic acid content.

Keywords: Apple Peel, Malus domestica, oleanolic acid, total phenols, ursolic acid

\section{INTRODUCTION}

The apple fruit cuticle is $70-80 \%$ cutine, ${ }^{[1]}$ which is an insoluble biopolymer consisting of polyphenol esters of long-chain hydroxy-fatty acids, structurally merged with waxy material (20-30\%), free fatty acids, phenols and small amounts of pectin, cellulose and other compounds. ${ }^{[2]}$ This chemically diverse complex protects the fruit from water loss, insect attacks and other environmental threats. ${ }^{[3,4]}$ The lipophilic constituents of apple peel contain the pentacyclic

Address for correspondence:

Dr. Antonio C. Siani, Department of Natural Products,

Medicines and Drugs Technology Institute,

Oswaldo Cruz Foundation, Rua Sizenando Nabuco 100,

Manguinhos, 21041-250, Rio de Janeiro, RJ, Brazil.

E-mail:siani@far.fiocruz.br triterpenes ursolic (UA) and oleanolic acids (OA) that are molecules bearing a secondary hydroxyl group at C-3 and a polar carboxyl group at C-17 [Figure 1]. These acids possess a plethora of pharmacological activities, including anti-inflammatory, antitumoral, anti-hepatitis, etc. ${ }^{[5,6]}$ Separation of these acids from vegetal matrices usually employs organic solvents, such as ethanol, chloroform and $n$-hexane..$^{[7-9]}$ However, efficient processes to separate these acids from apple peels must overcome some physical and chemical barriers that ordinarily hamper the extraction process: (i) The poor solubility of the triterpene acids in environmentally friendly solvents, including alcohol and low-carbon-chain esters; ${ }^{[9,10]}$ (ii) The inherent ability of each solvent to penetrate the highly lipophilic matrix; ${ }^{[4,11,12]}$ and (iii) The co-extraction of varying amounts of other compounds from the peel epidermis, especially the cutin complex that 


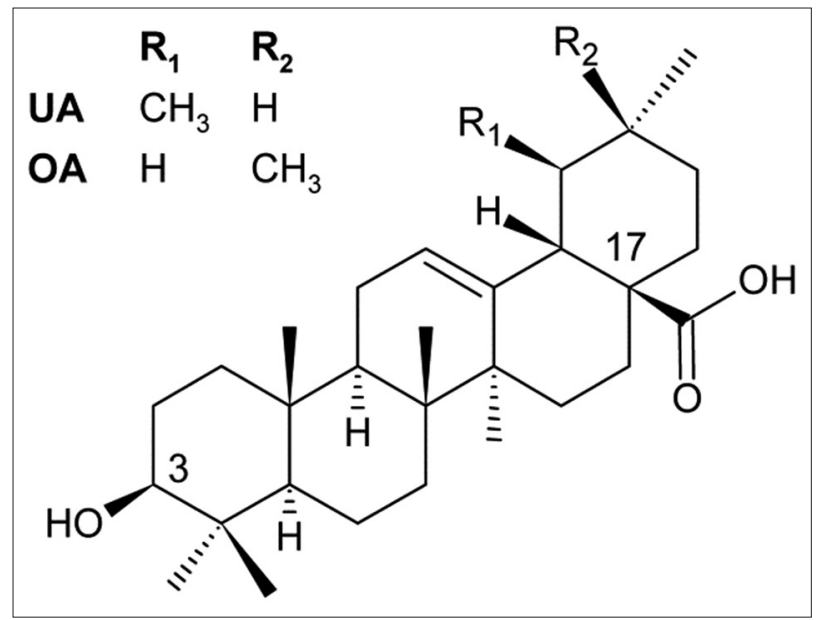

Figure 1: Structures of ursolic acid and oleanolic acid

drastically diminishes the extract's solubility in either organic or aqueous solvents ${ }^{[13]}$ and provides an intractable consistency to the extracts. ${ }^{[14]}$ This study assesses the hydroethanolic static maceration during 180 days at room temperature as an extraction system for UA and OA from apple peels ${ }^{[15]}$ to find the best period to maximize the selective yields. The apple peels were also simultaneously decocted at the same drug: extract ratio (DER) to compare with the overall yield and triterpene contents of the hydroethanolic extract. The amounts of extracted UA and OA were quantitatively assessed using HPLC-DAD techniques. The obtained extracts were also evaluated for their total phenolic content using the Folin-Ciocalteau method to establish the processes' selectivity.

\section{Experimental}

\section{Materials and chemicals}

Medium sized commercial fruits of Malus domestica Borkh. cv. Fuji $(15.0 \mathrm{~kg})$ were purchased at the central supplier of food and grocery (CEASA) in the municipality of Campinas, São Paulo state in Brazil. The fruits were peeled using a manual kitchen peeler to obtain thin slices of fresh material that was thrice and intermittently oven-dried at $100^{\circ} \mathrm{C}$ for $4 \mathrm{~h}$, followed by 7 more days at $45^{\circ} \mathrm{C}$, under constantly flowing air. The resulting pieces of peel $(442.3 \mathrm{~g}, 2.95 \%)$ were ground using a kitchen blender and mechanically sieved (Bertel, Brazil) to furnish particles between 850-1000 $\mu \mathrm{m}$. The standards for ursolic ( $>90 \%$ purity) and oleanolic $(>97 \%$ purity) acid were purchased from Sigma-Aldrich Co. (articles U6753 and O5504, respectively) (St Louis, MO, USA). The hydroalcoholic extracts were prepared using analytical grade ethanol (Merck, Darmstadt, GE). Trifluoroacetic acid, acetonitrile and methanol (HPLC/UV grade) were acquired from Tedia (Fairfield, OH, USA) and used throughout the chromatographic analysis with ultrapurified water (resistivity of $18.1 \mathrm{M} \Omega-\mathrm{cm}$ ) from a NanoPure Diamond system (Barnstead/Thermolyne, Dubuque, IA, USA). The gallic acid was purchased from Aldrich
Chemical Co. (Milwaukee, WI, USA), the ethanol and sodium carbonate from Vetec (Xerém, Brazil) and the Folin-Ciocalteau reagent from Fluka (Sigma Chemical Co., St Louis, MO, USA).

\section{Extracts preparation}

Aqueous extract of apple peels

A suspension of dry milled Fuji apple peels $(3.0 \mathrm{~g})$ in distilled water $(30 \mathrm{ml})$ was boiled in a $125 \mathrm{ml}$ Erlenmeyer flask for $10 \mathrm{~min}$. The mixture was passed through filter paper (Whatman grade 4), cooled to room temperature and subsequently lyophilized (equipment Christ model Beta 1-16, Merrington, UK) to produce the crude 'decoction' aqueous extract.

\section{Drug-extract ratio assay for the hydroethanolic extract of apple peels}

Two samples $(5.0 \mathrm{~g})$ of dry Fuji apple peels were placed in $25 \mathrm{ml}$ and $125 \mathrm{ml}$ Erlemeyer flasks containing $10 \mathrm{ml}$ and $50 \mathrm{ml}$ of an ethanol: water $(7: 3 v / v)$ mixture to perform 50 and $10 \%$ DER, respectively. These flasks were left standing at room temperature for $48 \mathrm{~h}$ and subsequently heated at $60^{\circ} \mathrm{C}$ for $4 \mathrm{~h}$ with gentle stirring. Both extracts were passed through filter paper (Whatman grade 4) and allowed to cool to room temperature. A portion of the solvent was removed by rotary evaporation and the aqueous residue was lyophilized to afford the crude extracts.

\section{Hydroethanolic static maceration of apple peels}

Fifteen samples of dry Fuji apple peels $(5.0 \mathrm{~g})$ were extracted at room temperature in $50 \mathrm{ml}$ of ethanol: water $(7: 3 v / v)$ over two to 180 days. The crude apple peel 'tincture' samples were generated using paper filtration (Whatman grade 4), removal of the solvent by rotary evaporation and subsequently lyophilizing the aqueous residue.

HPLC determination of ursolic and oleanolic acids in the extracts

\section{Calibration curves for ursolic and oleanolic acids}

To prepare the standard solutions, $10 \mathrm{mg}( \pm 0.01 \mathrm{mg}$ precision) aliquots of each standard were diluted with methanol to $25 \mathrm{ml}$ in a volumetric flask, obtaining complete dissolution at $400 \mu \mathrm{g} / \mathrm{ml}$. From this solution, 100, 200, 500,1250 and $2500 \mu \mathrm{l}$ aliquots were transferred to separate $5 \mathrm{ml}$ volumetric flasks and diluted with methanol to obtain concentrations of $8,16,40,100$ and $200 \mu \mathrm{g} / \mathrm{ml}$, respectively. The standard solutions were injected into the HPLC system in triplicate to generate the calibration curves, as well as evaluate the linearity and validity using the ANOVA test.

\section{Quantitation of ursolic and oleanolic acids in the extracts}

The samples were weighed ( $\pm 0.01 \mathrm{mg}$ precision) and diluted to $50 \mathrm{mg} / \mathrm{ml}$ with methanol; the mixtures were 
sonicated for $15 \mathrm{~min}$ and then filtered through centrifugal filter devices (Durapore, PVDF membrane, $0.2 \mu \mathrm{m}$ ) to determine the ursolic and oleanolic acids content by HPLC-DAD. Each triterpenoid acid was quantified based on the appropriate standard curve.

\section{Chromatography system}

The liquid chromatography system (Merck-Hitachi, Japan), LaChrom, consisted of a quaternary L-7100 pump, an L-7614 degasser, an L-7250 autosampler, an L-7360 column oven and an L-7455 photodiode array detector (PDA) scanning at $200-800 \mathrm{~nm}$ with a $1 \mathrm{~nm}$ resolution. The data analysis was performed with the D-7000 interface and System Manager v. 4.1 (Merck-Hitachi). The column used was a $250 \times 4.6 \mathrm{~mm}$ SymmetryShield RP18 $5 \mu \mathrm{m}$ (Waters, Ireland) connected to a Supelguard LC-18 guard column $(2 \mathrm{~cm}$, Supelco, Bellefonte, PA, USA). Isocratic elution for a total run time of $35 \mathrm{~min}$ was carried out at $30^{\circ} \mathrm{C}$ and at flow-rate $0.6 \mathrm{ml} / \mathrm{min}$ in a mobile phase consisting of $98: 2 v / v$ acetonitrile and $1.25 \% \mathrm{v} / \mathrm{v}$ phosphoric acid aqueous solution. The injection volume was $20 \mu \mathrm{l}$. The chromatograms were monitored by UV detection at $206 \mathrm{~nm}$. The peaks at 22.7 and $23.7 \mathrm{~min}$ in the samples were identified as oleanolic and ursolic acids, respectively, by comparing the retention times to the standards and the similarity of their UV spectra.

\section{Assessment of the total phenols using the}

\section{Folin-Ciocalteau method}

\section{Sodium carbonate solution}

A solution was prepared by boiling $200 \mathrm{~g}$ of anhydrous sodium carbonate in $800 \mathrm{ml}$ of water. After cooling, it was seeded with few crystals of sodium carbonate and allowed to stand for $24 \mathrm{~h}$ at room temperature. The material was passed through filter paper and the final volume was diluted to 1 liter with water.

\section{Analytical curve of gallic acid}

Gallic acid $(0.5 \mathrm{~g})$ was dissolved in methanol $(10 \mathrm{ml})$ and diluted to $100 \mathrm{ml}$ with water $(5 \mathrm{~g} / \mathrm{l} \mathrm{final})$. Aliquots containing $1,2,5$ and $10 \mathrm{ml}$ of this solution were diluted with water in $100 \mathrm{ml}$ volumetric flasks to attain concentrations of 50,100, 250 and $500 \mu \mathrm{g} / \mathrm{ml}$, respectively. These solutions were subjected to Folin-Ciocalteau reagent ${ }^{[16]}$ (see below), the calibration curve was obtained and its linearity was evaluated.
Quantitative residual phenols and polyphenols in the apple peel extracts

Total phenolic analysis using the Folin-Ciocalteau assay was performed using the same procedure as was used for gallic acid, but the extract samples were used instead at $50 \mathrm{mg} / \mathrm{ml}$ in methanol. A gallic acid standard solution $(20 \mu \mathrm{l})$, a sample solution $(50 \mathrm{mg} / \mathrm{ml}$ ) or a blank (purified water) sample was placed in a $4 \mathrm{ml} \mathrm{vial,} \mathrm{followed} \mathrm{by} \mathrm{addition} \mathrm{of} \mathrm{water}(1.58 \mathrm{ml})$ and Folin-Ciocalteau reagent $(100 \mu \mathrm{l})$. After thorough mixing, the mixtures were allowed to stand for two minutes at room temperature, followed by the addition of sodium carbonate solution $(300 \mu \mathrm{l})$. This final mixture was allowed to stand at room temperature for two hours. Afterward, $200 \mu \mathrm{l}$ aliquots were transferred to a polystyrene 96-well Elisa microplate (BioTek, VT, USA) and the absorbance was measured at $760 \mathrm{~nm}$. The analysis was performed in triplicate. The data were processed using Microsoft Office Excel (Microsoft, USA) and the results were expressed as gallic acid equivalent $(\mathrm{mg}) / \mathrm{g}$ extract (GAE).

\section{RESULTS AND DISCUSSION}

\section{Extract yields}

As expected, the aqueous extract contained less triterpene due to low solubility and the large amount of water-insoluble cutine and lipophilic compounds in the peel [Table 1]. Two different DERs were initially assayed to asses which procedure attained a better crude extract yield. The half yield resulted from employing 50\% compared to $10 \%$ DER in the preliminary hydroalcoholic maceration $(22 \%$ and $45 \%$ of crude extract, respectively). Higher DER in the solvents might favor the release of polar compounds therefore saturating the medium and hampering the solvation of the major lipophilic apple peel constituents. The higher relative amount of polar compounds that appear before the triterpene acids during HPLC analysis of the most concentrated extraction [Figure 2c] partially supports this assumption. Additionally, a five-fold amount of total triterpene acid $(P<0.05)$ was extracted after macerating the extract employing $10 \%$ versus $50 \%$ DER. These preliminary results supported the use of $10 \%$ DER for the long-term experiment.

Table 2 displays the yields obtained from the 180 day apple peel maceration in ethanol:water 7:3 v/v (tincture).

\begin{tabular}{|c|c|c|c|c|c|c|}
\hline Process & DER (\%) & Yield (\%) & UA (yield) & OA (yield) & UA+OA (yield) & Total phenols (mg GAE/g) \\
\hline Decoction & 10 & 32.0 & $0.01 \pm 0.00 \%$ & $0 \pm 0.00$ & $0.01 \pm 0.00 \%$ & $6.75 \pm 0.19$ \\
\hline Tincture $48 \mathrm{~h}$ & $\begin{array}{l}10 \\
50\end{array}$ & $\begin{array}{l}44.6 \\
21.7\end{array}$ & $\begin{array}{l}0.97 \pm 0.07 \% \\
0.17 \pm 0.04 \%\end{array}$ & $\begin{array}{l}0.33 \pm 0.02 \% \\
0.09 \pm 0.02 \%\end{array}$ & $\begin{array}{l}1.30 \pm 0.07 \% \\
0.26 \pm 0.04 \%\end{array}$ & $\begin{array}{l}11.65 \pm 0.76 \\
10.71 \pm 0.35\end{array}$ \\
\hline
\end{tabular}

SD: Calculated from triplicates; DER:Drug extract ratio; UA:Ursolic acid; OA:Oleanolic acid; Total phenols expressed in gallic acid equivalent (GAE) 


\begin{tabular}{|c|c|c|c|c|c|}
\hline Maceration period (days) & Yield (\%) & $\mathrm{UA}(\mathrm{mg} / \mathrm{g})$ & $\mathrm{OA}(\mathrm{mg} / \mathrm{g})$ & $U A+O A(m g / g)$ & Total phenols (mg GAE/g) \\
\hline 2 & 49.9 & $4.35 \pm 0.01$ & $2.25 \pm 0.01$ & $6.60 \pm 0.01$ & $9.13 \pm 0.99$ \\
\hline 4 & 42.7 & $4.65 \pm 0.04$ & $2.34 \pm 0.02$ & $6.99 \pm 0.04$ & $9.13 \pm 0.59$ \\
\hline 6 & 48.2 & $4.63 \pm 0.01$ & $2.25 \pm 0.01$ & $6.88 \pm 0.01$ & $7.94 \pm 0.61$ \\
\hline 8 & 45.8 & $4.66 \pm 0.03$ & $2.36 \pm 0.01$ & $7.02 \pm 0.03$ & $8.86 \pm 0.85$ \\
\hline 10 & 39.2 & $5.35 \pm 0.10$ & $3.30 \pm 0.11$ & $8.65 \pm 0.15$ & $6.97 \pm 0.87$ \\
\hline 12 & 50.3 & $6.12 \pm 0.09$ & $3.13 \pm 0.04$ & $9.25 \pm 0.10$ & $7.88 \pm 1.14$ \\
\hline 15 & 39.7 & $4.97 \pm 0.02$ & $3.05 \pm 0.01$ & $8.02 \pm 0.02$ & $10.66 \pm 1.24$ \\
\hline 20 & 41.2 & $4.95 \pm 0.03$ & $2.94 \pm 0.02$ & $7.89 \pm 0.04$ & $9.00 \pm 1.00$ \\
\hline 30 & 38.2 & $5.16 \pm 0.02$ & $3.28 \pm 0.03$ & $8.44 \pm 0.04$ & $11.57 \pm 1.05$ \\
\hline 40 & 50.1 & $4.69 \pm 0.03$ & $2.39 \pm 0.02$ & $7.08 \pm 0.04$ & $9.62 \pm 1.34$ \\
\hline 50 & 50.6 & $4.97 \pm 0.03$ & $2.50 \pm 0.01$ & $7.47 \pm 0.03$ & $10.03 \pm 0.59$ \\
\hline 60 & 49.7 & $4.85 \pm 0.05$ & $2.50 \pm 0.03$ & $7.35 \pm 0.06$ & $9.71 \pm 0.66$ \\
\hline 90 & 49.3 & $4.33 \pm 0.05$ & $2.34 \pm 0.02$ & $6.67 \pm 0.05$ & $9.61 \pm 1.36$ \\
\hline 120 & 48.8 & $3.86 \pm 0.00$ & $2.19 \pm 0.00$ & $6.05 \pm 0.00$ & $9.01 \pm 1.01$ \\
\hline 180 & 47.4 & $3.63 \pm 0.03$ & $2.12 \pm 0.02$ & $5.75 \pm 0.04$ & $8.86 \pm 1.41$ \\
\hline
\end{tabular}

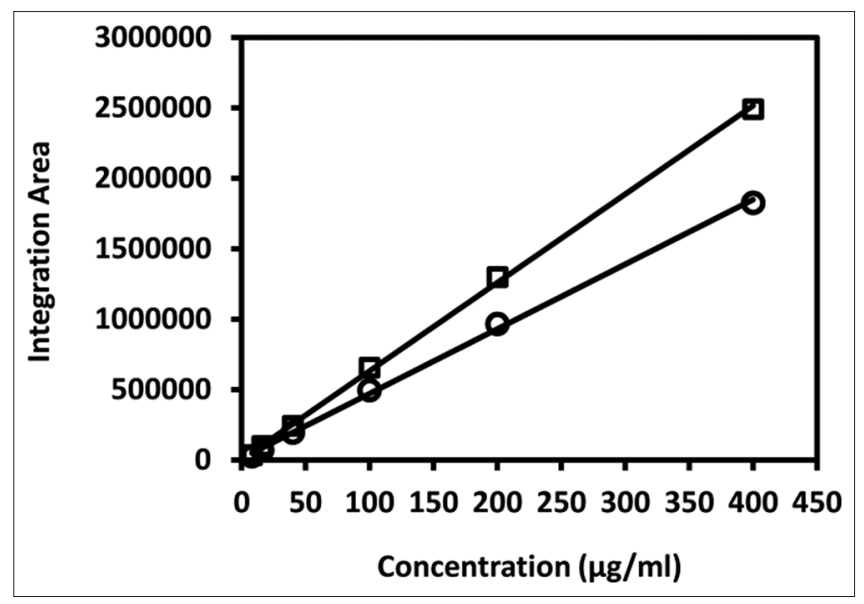

Figure 2: HPLC calibration curves of ursolic acid (circle) and oleanolic acid (square) obtained by monitoring at $206 \mathrm{~nm}$

Differences in the yield relative to the period of extraction may arise from the non-homogenous raw material caused by the manual peeling of the apples. This process produces particles of different sizes and thicknesses that cannot be made uniform relative to the dry cuticle and residual apple pulp content, even after sieving. The lowest yield was obtained after 10-day maceration (39.2\%) and the highest yield was received after 50 days (50.6\%), although no large variations were observed during the period tested.

\section{Quantitative HPLC analysis of ursolic and oleanolic} acids

\section{General HPLC aspects}

In recent years, more systematic studies have been conducted on triterpene acid dereplication from plant matrices and characterization by HPLC with UV detection. ${ }^{[17-19]}$ Separation conditions were usually achieved with a reversed phase column filled with C-18 particles between 3 and $5 \mu \mathrm{m}$ and sample elution with acetonitrile or methanol alongside buffered acetic or phosphoric acid media. The triterpene acids are weak chromophores that are usually detected between 205 and $220 \mathrm{~nm}$. In the current study, the UA and OA contents were determined using the chromatographic method reported by Chen et al. (2003), ${ }^{[20]}$ with a few adjustments to improve resolution and performance. UA and OA were satisfactorily separated under the selected chromatographic conditions with retention times of approximately 23.50 and $22.50 \mathrm{~min}$, respectively.

\section{Calibration curve}

The calibration curves displayed excellent linearity $\left(\mathrm{R}^{2}>0.9995\right)$ and good reproducibility was achieved with $<5 \%$ RSD for the integration areas at all concentrations. The regression equations were $y=4,590,000 x+12,800$ and $y=6,274,000 x+5,000$ [Figure 2], for ursolic and oleanolic acids, respectively, where $x$ is the concentration of triterpene acid in $\mu \mathrm{g} / \mathrm{ml}$ and $y$ is the mean integrated area.

Assessment of triterpene acid contents in the extracts Typical chromatograms for decoction and tincture extracts are displayed in [Figure 3].

The acid contents in the extracts were calculated based on the calibration curves [Table 2]. Relative to the total triterpene acid extracted from the apple peel matrix, the highest yields for the hydroethanolic (7:3) maceration were obtained between 12 and 30 days, but the yields gradually decreased up to 180 days. UA extraction was optimal after macerating for 12 days $(6.12 \mathrm{mg} / \mathrm{g})$, while maceration for 10 or 30 days maximized the OA yield $(3.30 \mathrm{mg} / \mathrm{g})$. Across the entire assay period, the ratio of UA/OA in the extracts ranged from 1.57 to 2.05. After approximately 


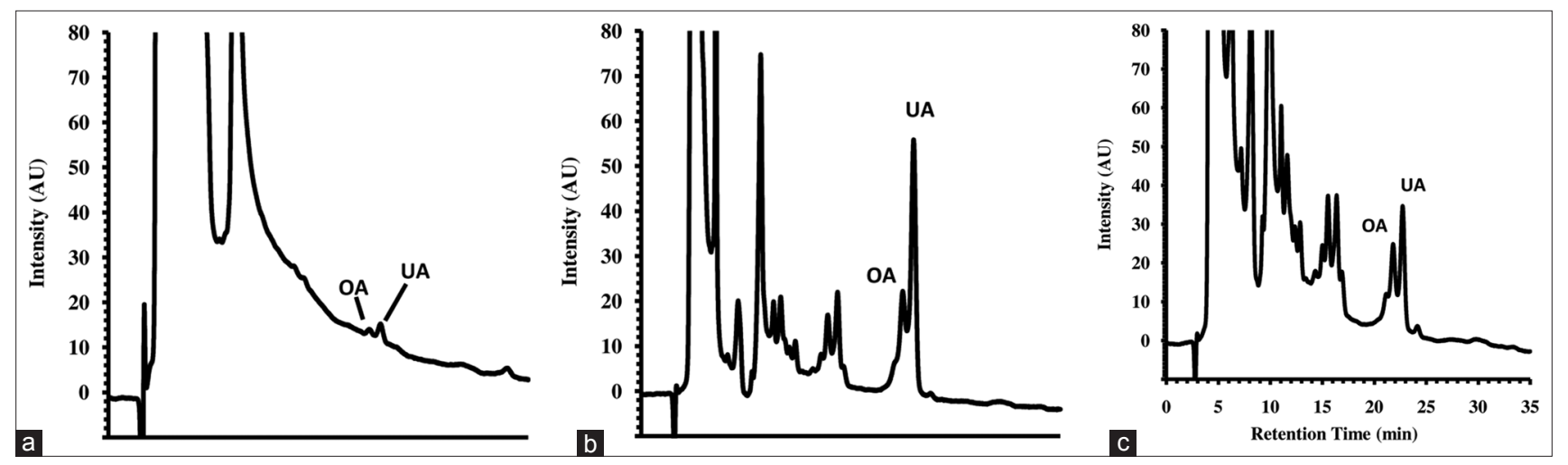

Figure 3: Typical HPLC chromatograms of apple peels extract $(206 \mathrm{~nm})$ : (a) decoction; (b) tincture $48 \mathrm{~h}$ at $10 \%$ DER and (c) tincture $48 \mathrm{~h}$ at $50 \%$ DER. OA = oleanolic acid; UA = ursolic acid

50 days, the concentrations of both acids decreased slightly until 180 days. These results are consistent with the progressive precipitation of these compounds in standing water-ethanol mixtures. The precipitation process favors the less soluble UA, reflecting the gradual decrease in the soluble proportion of $\mathrm{UA} / \mathrm{OA}$ toward the end of the testing period. Additionally because $\mathrm{OA}$ is usually more soluble than $\mathrm{UA},{ }^{[10,21]}$ a more significant relative amount of the former is expected when the acids yields are low.

Regarding the raw material, higher yields were obtained during approximately the same 12-day (UA: $308 \mathrm{mg} / 100 \mathrm{~g}$; OA: $157 \mathrm{mg} / 100 \mathrm{~g}$ dry apple peels) and 30-day extraction (UA: $197 \mathrm{mg} / 100 \mathrm{~g}$; OA: $125 \mathrm{mg} / 100 \mathrm{~g}$ ). The acid concentration produced by the raw material at DER 1:10 with a 0.7 co-solvent (ethanol) ratio after the 180-day maceration at room temperature yielded $4.74 \mathrm{mg} / \mathrm{g}$ UA and $2.59 \mathrm{mg} / \mathrm{g}$ OA on average, corresponding to $0.218 \mathrm{mg} / \mathrm{ml}$ and $0.119 \mathrm{mg} / \mathrm{ml}$, respectively. These concentrations are lower than the levels reported by Jin et al. (1997), ${ }^{[21]}$ who found values between $0.6-0.8 \mathrm{mg} / \mathrm{ml}$ when working with saturated solutions of individual acids at the same co-solvent ratio after $48 \mathrm{~h}$. When employing hydroethanolic mixtures, the pure acids began to dissolve when the volume fraction of the co-solvent (ethanol) was over 0.6, following an outstanding exponential trend from 0.8 up to 1.0 when the acids concentrations approached $5-6 \mathrm{mg} / \mathrm{ml} .{ }^{[21]}$ The use of a co-solvent was assayed to handle UA and OA under therapeutic conditions because triterpenoid acids are quite insoluble in aqueous media at neutral $\mathrm{pH}$, hindering their application to biological systems. ${ }^{[13,21]}$

All these results must be accounted for the manufacture of medicinal tinctures because the concentration values obtained experimentally might represent an exhaustive removal of triterpenes from the dry apple peel matrix with 7:3 mixtures of ethanol: water. These findings, beside the statistical uniformity for the observed UA and OA contents, suggest that the optimum amount of triterpene acids have been reached in the specific conditions assayed in the study.
The hydroethanolic extracts of apple peels always furnished lower triterpene contents than were obtained with less polar organic solvents, such as chloroform, during extraction of the dry peels. ${ }^{[6,8,9,2]}$ The separation efficiency for removing the triterpene acids from the matrix depends upon their solubility in the extraction solvent. Apart from the amounts of these metabolites in the cuticle relative to the apple type and the ontogenetic levels of the fruit, ${ }^{[2,24]}$ the extraction solvent and protocol may account for any discrepancies. The inherent physicochemical conditions during the extraction process, specifically the low molecular diffusion through the waxy matrix and the acids' interaction with other substances present in the peel, such as the fatty acids, have been examined by some authors. For instance, the aqueous extraction of mistletoe produced concentrations of oleanolic acid up to 10 times greater than the same conditions applied to solvate only the acid. ${ }^{[13]}$ Additionally, blends of both triterpene acids have been reported as more soluble in organic solvents, especially alcohols, than either compound individually. ${ }^{[25]}$

\section{Total phenols in the extracts}

The calibration curve that was constructed using different concentrations of gallic acid in methanol in relation to the Folin-Ciocalteau reagent and reading at $760 \mathrm{~nm}$ generated the equation $y=0.0008 x+0.0198$, which displays good linearity $\left(R^{2}=0.9992\right)$ between 50 and $500 \mu \mathrm{g} / \mathrm{ml}$. Table 2 displays the total phenol content of the apple peel extracts relative to the solvent and maceration period. The average total phenol content of the hydroethanolic extracts varied from the minimum at 10 days $(6.97 \mathrm{mg} / \mathrm{g})$ to the maximum at 30 days $(11.57 \mathrm{mg} / \mathrm{g})$. However, the average variation did fit into a constant uncertainty range. The largest amounts of residual phenols in the extracts were observed between 15 (10.66 mg GAE/g) and 90 (9.61 mg GAE/g) days [Figure 4]. These values were close to those obtained by ultrasound-accelerated extraction (data not shown) but were approximately half less than the reported value for the total phenols extracted with high-speed homogenization of dry apple peels using chilled aqueous $80 \%$ ethanol or $80 \%$ acetone. ${ }^{[12,26]}$ 


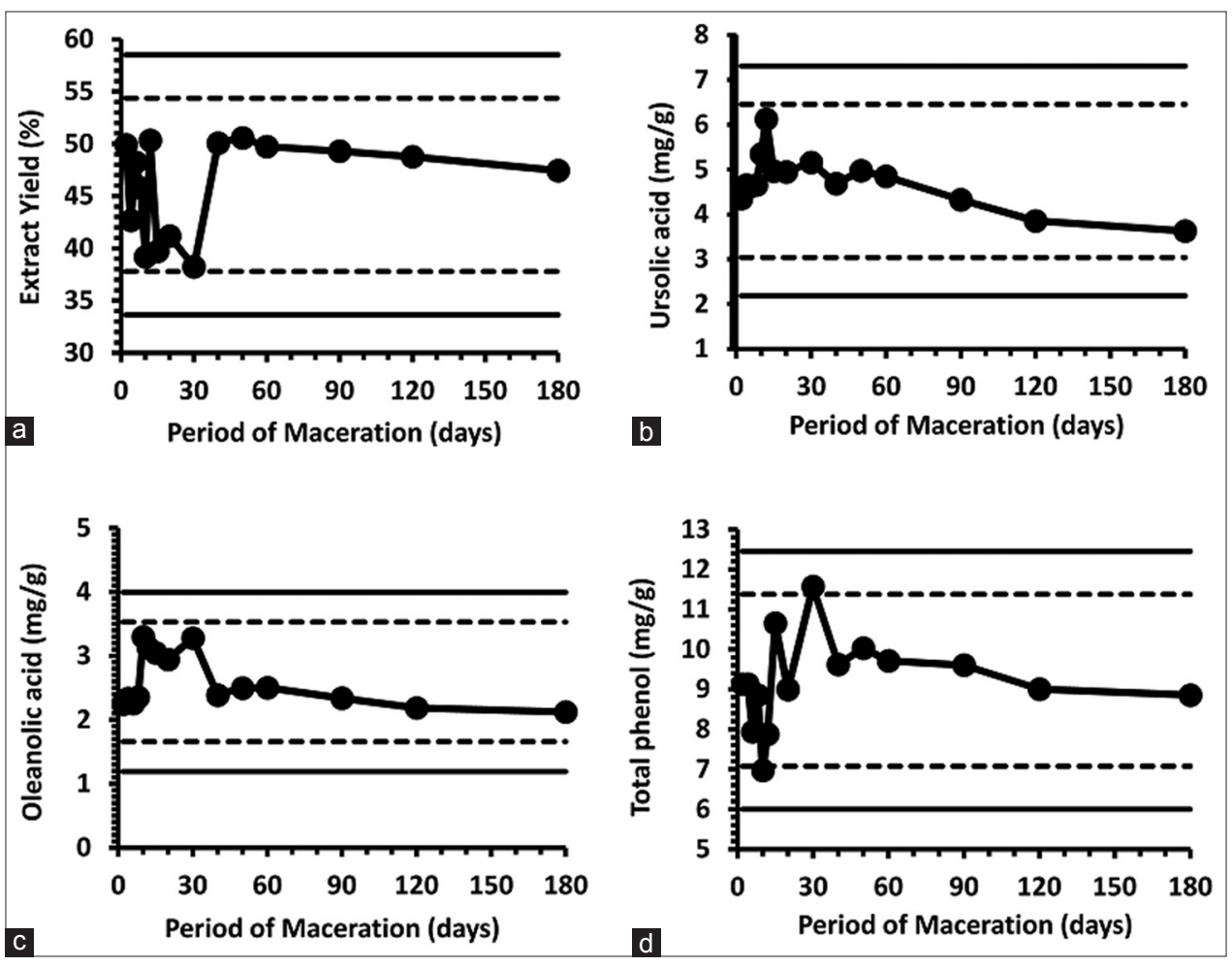

Figure 4: Control Charts showing the evaluated characteristics of the extracts within the confidence limits on the maceration process:(a) Extraction yield (\%); (b) ursolic acid and (c) oleanolic acid contents determined by HPLC-DAD; (d) total phenol content by Folin-Ciocalteau test. Control limits with 99\% (solid) and 95\% (dashed) confidence are indicated (see Table 3)

Extracting lower amounts of phenols with more triterpene acids would result in selective enrichment of the latter. This phenomenon occurred between 10 and 30 days of maceration, a fact that notes to the choice of this period for more selective extraction. Furthermore, some selectivity in the triterpene extraction occurs between 10 and 12 days, although the crude extract also afforded lower yields during this period.

Figure 4 presents the Control Charts for the measured variables; these parameters are representative of the maceration process and of the extracts: yield ratio calculated by mass, UA and OA contents determined by HPLC analyses and the total phenolic contents assessed with the spectrophotometric Folin-Ciocalteau test. The limits of the 95 and $99 \%$ confidence intervals were determined from variations in the respective measurements and are displayed in Table 3. Only two abnormal points were found when the $95 \%$ confidence limits (total phenolic content at 10 and 30 days), but they were still within the $99 \%$ confidence intervals. Therefore, no significant variation could be observed in the period between two and 180 days for any evaluated variable. Good repeatability ( $<18 \%$ RSD) was achieved with this maceration protocol. These statistically constant properties are standards for the Fuji apple peel tinctures obtained by macerating the raw material in ethanol:water $(7: 3 v / v)$ at room temperature. These

\begin{tabular}{|c|c|c|}
\hline Confidence & $95 \%$ & $99 \%$ \\
\hline Extraction yield (\%) & $37.8-54.4$ & $33.6-58.5$ \\
\hline Ursolic acid content (mg/g) & $3.0-6.5$ & $2.2-7.3$ \\
\hline Oleanolic acid content $(\mathrm{mg} / \mathrm{g})$ & $1.7-3.5$ & $1.2-4.0$ \\
\hline Total phenol content $(\mathrm{mg} / \mathrm{g})$ & 7.2-11.4 & $6.0-12.5$ \\
\hline
\end{tabular}

results are valuable when researching triterpene acid-based medicinal preparations. A mixed batch prepared from all the samples at different times possessed $5.61 \pm 0.08 \mathrm{mg} / \mathrm{g}$ $\mathrm{UA}, 2.16 \pm 0.06 \mathrm{mg} / \mathrm{g} \mathrm{OA}$ and $9.66 \pm 1.73 \mathrm{mg} / \mathrm{g}$ gallic acid equivalents; these values are also within the control limits established in this work [Table 3].

\section{CONCLUSION}

Extracts obtained from dry Fuji apple peels using static maceration in ethanol:water $(7: 3 v / v)$ at room temperature and $10 \%$ DER generated overall yields varying from 40-50\%, which are averagely constituted by 6.1 and $3.3 \mathrm{mg} / \mathrm{g}$ of ursolic and oleanolic acids, respectively. Variations in the main parameters related to the maceration process (weight yield) and the chemical composition (ursolic acid, oleanolic acid and total phenol contents) of the extracts produced 
during the approached period were considered not statistically significant. A period of 10 to 30 days may be adequate to obtain extracts enriched in triterpenoid acids with a minimal amount of undesirable phenols using the assayed conditions. These results establish parameters to obtain standardized tinctures from this specific raw material in terms of the triterpene acid-based medicinal content.

\section{REFERENCES}

1. Neubeller J. Beziehungen zwischen der Wasserabgage von Äpfeln und der Zusammensetzung der Fruchtschale. Z Lebensm Unters Forsch 1971;147:86-93.

2. Huelin FE, Gallop RA. Studies in the natural coating of apples. I. Preparation and properties of fractions. Aust J Sci Res 1951;494:526-33.

3. Kolattukudy PE. Natural waxes on fruits. Postharvest PomolNewsl1984;22. Available from: http://postharvest.tfrec. wsu.edu/REP2003A.pdf. [Last cited 2006 Dec 10].

4. Ju Z, William J, Bramlage WJ. Phenolics and lipid-soluble antioxidants in fruit cuticle of apples and their antioxidant activities in model systems. Postharvest Biol Technol 1999;16:107-11.

5. Liu J. Oleanolic acid and ursolic acid: Research perspectives. J Ethnopharmacol 2005;100:92-4.

6. Yamaguchi H, Noshita T, Kidachi Y, Umetsu H, Hayashi M, Funayama $\mathrm{S}$, et al. Isolation of ursolic acid from apple peels and its specific efficacy as a potent antitumor agent. J Health Sci 2008;54:654-60.

7. Ma CM, Cai SQ, Cui JR, Wang RQ, Tu PF, Hattori M, et al. The cytotoxicity activity of ursolic acid derivatives. Eur J Med Chem 2005;40:582-9.

8. Ellgardt K. Triterpenes in apple cuticle of organically and IP cultivated apples. Bachelor project, Danish-Swedish Horticulture programme, SverigesLantbruksUniversitet, Alnarp, Sweden, 2006.

9. Jäger S, Trojan H, Kopp T, Laszczyk MN, Scheffler A. Pentacyclic triterpene distribution in various plants - Rich sources for a new group of multi-potent plant extracts. Molecules 2009;14:2016-31.

10. Merck Research Laboratories. The Merck Index. $11^{\text {th }}$ ed. Rahay: Merck and Co. Inc.; 1989. Entries 6964 and 10027, p. 1171 and 1686.

11. Whitaker BD. Phenolic fatty-acid esters from the peel of 'Gala' apples and their possible role in resistance to superficial scald. Postharvest Biol Technol 1998;13:1-10.

12. Wolfe KL, Liu RH. Apple peels as valuable-added food ingredient. J Agric Food Chem 2003;51:1676-83.
13. Jäger $\mathrm{S}$, Winkler K, Pfüller U, Scheffler A. Solubility of oleanolic acid and betulinic acid in aqueous solutions and plant extracts of Viscum album L. Planta Med 2007;73:157-62.

14. Huelin FE. Studies in the natural coating of apples. Aust J Biol Sci 1959;12:175-80.

15. Pridgen $\mathrm{JH}$. Method and composition for relieving symptoms of arthritis and gout using fruit of miracles. USA Patent Appl. Pub. US 2005/0158410 A1, 07/21/2005.

16. Waterhouse AL. Determination of Total Phenolics. In: Wrolstad RE, Acree TE, Decker EA, Penner MH, Reid DS, Schwartz SJ, et al., editors. Current Protocols in Food Analytical Chemistry. New York: Wiley; 2002. p. I1.1.1-8.

17. Tian S, Shi Y, Yu Q, Upur H. Determination of oleanolic acid and ursolic acid contents in Ziziphora clinopodioides Lam. by HPLC method. Pharmacogn Mag 2010;6:116-9.

18. Lee $M K$, Ahn $Y M$, Lee $K R$, Jung $J H$, Jung OS, Hong $J$ Development of a validated liquid chromatographic method for the quality control of Prunellae Spica: Determination of triterpenic acids. Anal Chim Acta 2009;633:271-7.

19. Martelanc M, Vovk I, Simonovska B. Separation and identification of some common isomeric plant triterpenoids by thin-layer chromatography and high-performance liquid chromatography. J Chromatogr A 2009;1216:6662-70.

20. Chen JH, Xia ZH, Tan RX. High-performance liquid chromatographic analysis of bioactive triterpenes in Perilla frutescens. J Pharm Biomed Anal 2003;32:1175-9.

21. Jin IJ, Ko YI, Kim YM, Han SK. Solubilization of oleanolic acid and ursolic acid by cosolvency. Arch Pharm Res 1997;20:269-74.

22. Frighetto RT, Welendorf RM, Nigro EN, Frighetto, N, Siani AC Isolation of ursolic acid from apple peels by high speed counter-current chromatography. Food Chem 2008;106:767-71.

23. Markley KS, Sando CE. Progressive changes in the waxlike coating on the surface of the apple during growth and storage. J Agric Res 1931;42:705-22.

24. Markley KS, Sando CE. Progressive changes in the cuticle of apples during growth and storage. J Agric Res 1933;46:403-12.

25. Schneider P, Hosseiny SS, Szczotka M, Schlitter JK. Rapid solubility determination of the triterpenes oleanolic acid and ursolic acid by UV-spectroscopy in different solvents. Phytochem Lett 2009;2:85-7.

26. Massini L, Rico D, Diana AB, Barry-Ryan C. Valorisation of apple peels. Eur J Food Res Rev 2013;3:1-15.

Cite this article as: Siani AC, Nakamura MJ, dos Santos DS, Mazzei JL, do Nascimento AC, Valente LM. Efficiency and selectivity of triterpene acid extraction from decoctions and tinctures prepared from apple peels. Phcog Mag 2014;10:225-31.

Source of Support: Nil, Conflict of Interest: None declared. 